\title{
Expression of Recombinant Antigens in Escherichia coli: Application on Immunochemical Studies of Schistosoma mansoni Tegumental Antigens
}

\author{
Frederico GC Abath/ ${ }^{+}$, Edeneide M Xavier, Joanne D'Arc B Silva; Marcos A \\ Morais Junior*, Silvia ML Montenegro
}

\begin{abstract}
Laboratório de Bioquímica e Biologia Molecular, Departamento de Imunologia, Centro de Pesquisas Aggeu Magalhães-FIOCRUZ, Av. Moraes Rego s/n, Cidade Universitária, 50670-420 Recife, PE, Brasil *Departamento de Genética, Universidade Federal de Pernamubuco, Recife, PE, Brasil
\end{abstract}

Sm15 and Sm13 are recognized by antibodies from mice protectively vaccinated with tegumental membranes, suggesting a potential role in protective immunity. In order to raise antibodies for immunochemical investigations, the genes for these antigens were expressed in $p G E X$ and pMal vectors so that comparisons could be made among different expression systems and different genes. The fusion proteins corresponding to several parts of the gene for the precursor of Sm15 failed in producing antibodies recognizing the parasite counterpart. On the other hand, antibodies raised against Sm13 $M B P-f u s i o n$ proteins recognized the $13 \mathrm{kDa}$ tegumental protein. Thus the peculiarities of the gene of interest are important and the choice of the expression system must sometimes be decided on an empirical basis.

Key words: Schistosoma mansoni - tegumental antigens - fusion proteins

Gene cloning and expression can provide an abundant source of eukaryotic polypeptides. In this respect, several expression systems have been described, although all of them have advantages and disadvantages. Recombinant eukaryotic polypeptides synthesized in the Escherichia coli expression system, can differ from their authentic counterparts (Marston 1986), because there are a number of eukaryotic post-translational modifications which are not performed in E. coli. For example, glycosylation, acetylation and amidation. Sm15 and Sm13 are recognized by antibodies from mice protectively vaccinated with tegumental membranes (Smithers et al. 1990), suggesting a potential role in protective immunity. The complete gene for $\mathrm{Sm} 15$ was cloned and sequenced (Abath et al. 1993); this antigen is synthesized as a precursor that is processed during maturation (Abath et al. 1994). The other antigen, $\mathrm{Sm} 13$, is a typical membrane protein with a carboxy-terminus hydrophobic domain (not

\footnotetext{
This study was supported by grants from UNDP/World Bank/WHO, special programme for research and technical trainng in tropical diseases (TDR), CNPq (Conselho Nacional de Pesquisa e Desenvolvimento Tecnológico) and FACEPE (Fundação de Amparo a Ciência e Tecnologia de Pernambuco).

${ }^{+}$Corresponding author. Fax: +55-81-453.1911

Received 16 April 1997

Accepted 30 June 1997
}

published). In order to raise antibodies for immunochemical investigations, the genes encoding these tegumental antigens of Schistosoma mansoni were subcloned in pGEX and pMal expression vectors and the results compared.

\section{MATERIALS AND METHODS}

Parasites and homogenates were obtained as described previously (Abath et al. 1994). Tegumental outer membranes of adult worms were prepared according to Simpson et al. (1981). The samples were stored at $-20^{\circ} \mathrm{C}$.

Anti-sera against the fusion proteins were raised in rabbits by injecting $200 \mu \mathrm{g}$ of fusion protein with complete Freund's adjuvant subcutaneously, followed by 3 boosts. Rabbit anti-tegumental membrane antibodies $(\mathrm{R} \alpha \mathrm{M})$ were raised with tegumental membrane proteins solubilized in SDS (Simpson et al. 1990).

Affinity purified antibodies were prepared by plating out the $\lambda$ gt 11 A70 cDNA clone (2847-4327 of the gene for the precursor of Sm15) and adsorbing the $\beta$-galactosidase fusion proteins onto IPTG (isopropyl $\beta$-D-thiogalactopyranoside) soaked nitrocellulose filters. The affinity matrix prepared by adsorbing expression proteins directly from phage plaque lifts onto nitrocellulose was then incubated with rabbit antiserum. Affinity selected antibodies were then eluted from the filters with $\mathrm{pH}$ 2.6 glycine buffer and neutralized with Tris- $\mathrm{HCl} \mathrm{pH}$ 8.0 (Lyon \& Weber 1988). These antibodies were 
called A70RaM and recognized specifically a 15 $\mathrm{kDa}$ tegumental antigen (Sm15).

Sodium dodecyl-sulphate polyacrylamide gel electrophoresis (SDS-PAGE) was carried out as described by Laemmli (1970). The transfer of proteins from polyacrylamide gels to nitrocellulose filters was by semi-dry electroblotting using a discontinuous system in which filters saturated with buffer are layered from the anode plate in the following order: (1) $300 \mathrm{mM}$ Tris, $20 \%$ methanol, (2) 25 $\mathrm{mM}$ Tris, $20 \%$ methanol, (3) nitrocellulose membrane, (4) gel, (5) $40 \mathrm{mM} \varepsilon$-amino-n-hexanoic acid, $25 \mathrm{mM}$ Tris, $20 \%$ methanol. The immunodetection was undertaken essentially as described before (Abath et al. 1994).

The subcloning experiments were conducted according to standard procedures (Sambrook et al. 1989), polymerase chain reaction was used to engineer the inserts. Cells were made competent according to the procedure outlined by Chung et al. (1989). Transformed bacteria were grown and selected by standard methods (Sambrook et al. 1989). The expression and purification of glutathione Stransferase (GST) fusion proteins were performed according to Smith and Johnson (1988). To obtain the pure peptide, free of GST, the pGEX-2T fusion protein was thrombin cleaved within the beads (Abath \& Simpson 1990). When using pMal-cri (New England Biolabs), the expression and purification of the resulting MBP fusion proteins was carried out following the instructions of the supplier.

\section{RESULTS}

Subcloning of the genes for the precursor of Sm15 (GenBank L07513) and expression of fusion proteins in $E$. coli - The various constructs obtained are shown in Table with the respective inserts, apparent molecular weight of the resulting fusion proteins and the vectors used. The fusion proteins A70-20, A70H3-I9 and A70H1-G2 were found to show apparent molecular weights higher than predicted. The only difference between the A70-20 and A70H3-I9 constructs was the absence of the 3' untranslated region in the clone synthesizing the fusion protein A70H3-I9. The GST fusion, called 2TR7A corresponded to the regions of repeats of the precursor of Sm15 (Abath et al. 1994). The fusion protein A70H1-G2 was partially cleaved with thrombin within the agarose affinity matrix (Fig. 1A, lane 6). The peptide released from the $26 \mathrm{kDa}$ GST carrier by thrombin cleavage presented an apparent molecular mass of $45 \mathrm{kDa}$, higher than the predicted $18.5 \mathrm{kDa}$. This behaviour was observed for all the fusion proteins expressed and probably is due to the highly acidic composition of the sequence.

Antibody responses to fusion proteins - Antibodies raised in rabbits against the fusion protein A70-20, recognized in Western blots, the fusion proteins A70-20, A70H3-I9, A70H1-G2 and GST but only weakly recognized the polypeptide obtained following partial thrombin cleavage of the fusion protein A70H1-G2 (Fig. 1A). Furthermore, the anti-

TABLE

Pairs of primers used in $\mathrm{PCR}^{a}$, expected fragment sizes, gene sequence amplified and constructs obtained, corresponding fusion proteins, apparent molecular weight of the fusion protein and vector used

\begin{tabular}{|c|c|c|c|c|c|c|c|}
\hline Pairs of primers & Insert & Sequences & Construct & $\begin{array}{l}\text { Fusion } \\
\text { protein }\end{array}$ & $\begin{array}{l}\text { parent } \\
\text { N(kDa) }\end{array}$ & Vector & $\begin{array}{c}\text { Cloning } \\
\text { site }\end{array}$ \\
\hline \multicolumn{8}{|c|}{ Gene for the $S m 15$ precursor } \\
\hline lambda gt11 universal primers & s $1480 \mathrm{bp}$ & $2847-4327$ & A70-20 & A70-20 & 105 & pGEX-1N & EcoRI \\
\hline A70LH1 X A70RH2 & 1029 bp & $2847-3876$ & A70H3-I9 & A70H3-I9 & 105 & pGEX-2T & BamHI \\
\hline A70LH1 X A70CH1 & $501 \mathrm{bp}$ & $2847-3348$ & A70H1-G2 & A70H1-G2 & 60 & pGEX-2T & BamHI \\
\hline GA70FP3E X GA70RP0E & 1036 bp & $2102-3138$ & 2TR7A & 2TR7A & 110 & pGEX-2T & EcoRI \\
\hline ABF2 X ABR2 & $480 \mathrm{bp}$ & $1339-1819$ & pGEX1M2 (19) & GEXM2(19) & 60 & pGEX-1N & EcoRI \\
\hline A70LH1 X A70RH2 & 1029 bp & $2847-3876$ & pMcriH3(17) & McriH3(17) & 120 & pMal-cri & BamHI \\
\hline ABF2 X ABR2 & $480 \mathrm{bp}$ & $1339-1819$ & pMcriM2(7) & McriM2(7) & 66 & pMal-cri & EcoRI \\
\hline \multicolumn{8}{|c|}{ Gene for $\mathrm{Sm} 13$} \\
\hline lambda gt11 universal primers & s $380 \mathrm{bp}$ & $1-380$ & pMcriA 157 & McriA157 & 55 & pMal-cri & EcoRI \\
\hline
\end{tabular}

In the pGEX system fusions are produced with GST (26 kDa) of Schistosoma japonicum, while the pMal system produce fusions with maltose binding protein $(42 \mathrm{kDa})$. The sequence of these primers are available upon request. $a$ : polymerase chain reaction 


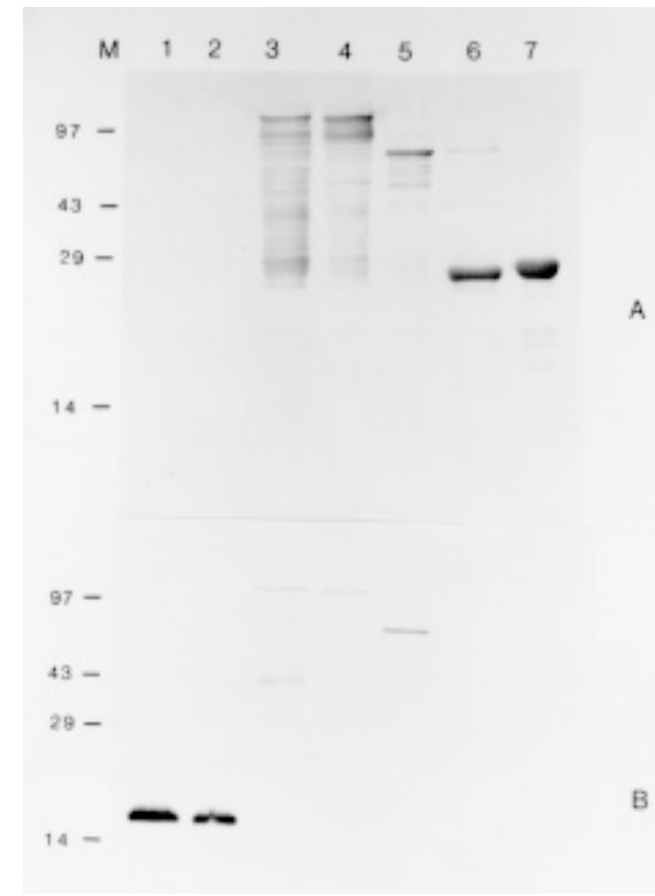

Fig. 1: Western blot probed with anti-A70-20 fusion protein antibodies (A) and selected antibodies reactive to the $15 \mathrm{kDa}$ antigen (B). Lane 1: adult tegumental membranes, lane 2: whole adult worm homogenate, lane 3: fusion protein A70-20, lane 4: fusion protein A70H3-I9, lane 5: fusion protein A70H1-G2, lane 6: fusion protein A70H1-G2 partially cleaved with thrombin, lane 7: GST. M: molecular weight markers.

bodies were not able to recognize Sm15 either in tegumental preparations or in adult whole worm homogenate. As can be seen in Fig. 1B, the fusion proteins A70-20, A70H3-I9 and A70H1-G2 were all recognized by antibodies specific to $\mathrm{Sm} 15$ $(\mathrm{A} 70 \mathrm{R} \alpha \mathrm{M})$. However, the products of thrombin cleavage: the specific peptide and GST were not recognized.

GST seemed to be very immunodominant in comparison to the recombinant proteins of the gene for the Sm15 precursor. Next, we subcloned the fragments corresponding to the pGEX clones A70-20 and pGEX1M2 in pMAL-cri (this vector encodes a different carrier). The resulting MBP fusion proteins were used to immunize rabbits and also failed in raising antibodies able to recognize the correspondent antigen in the parasite.

Expression of the gene for Sm13 (GenBank U67153) and immunogenicity of the fusion proteins - We described above the expression using two different vectors, of several parts of the gene for the precursor of Sm15 and the failure of the corresponding fusion proteins in eliciting an antibody

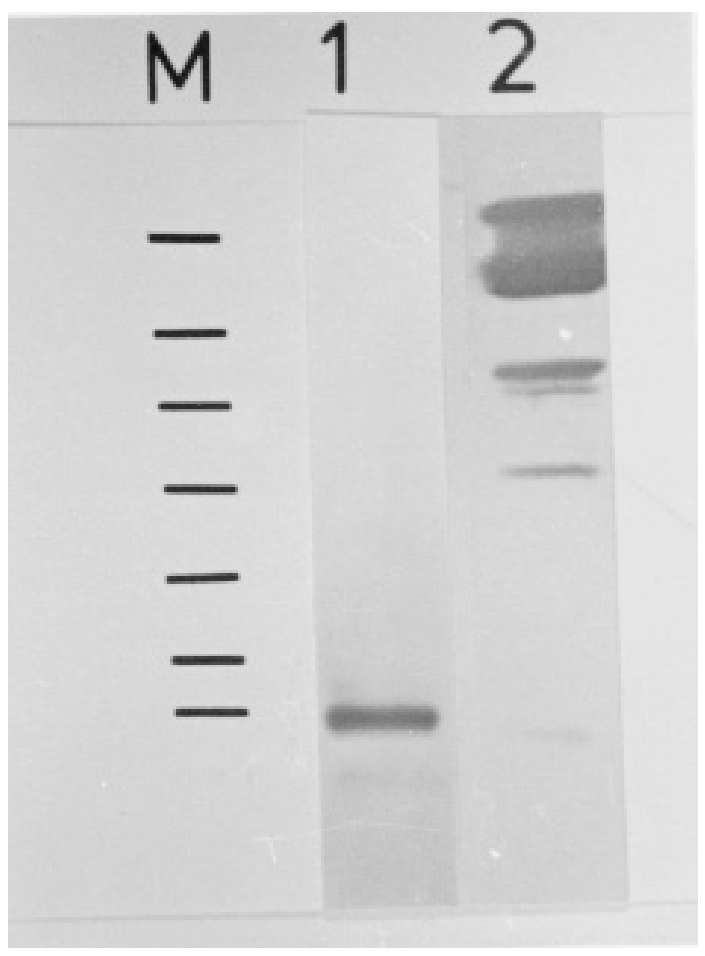

Fig. 2: Western blot probed with anti-McriA157 fusion protein antibodies. Lane 1: whole adult worm homogenate, lane 2: fusion protein McriA157. M: molecular weight markers: 200, 97, 68, 43, 29, 18, $14.3 \mathrm{kDa}$.

response capable of recognizing the parasite counterparts. The same strategy was used for the gene of Sm13. In this case the pMal-cri expression vector was used. Antibodies raised in rabbits against the Sm13 fusion protein McriA157 (Table) recognized in Western blot the $13 \mathrm{kDa}$ tegumental antigen (Fig. 2, lane 1). More detailed immunochemical studies about this atigen will be published elsewhere.

\section{DISCUSSION}

In order to obtain highly purified recombinant antigens in a non-denatured state, the genes for the $\mathrm{Sm} 15$ precursor and $\mathrm{Sm} 13$ were expressed in pGEX and pMal expression vectors so that comparisons could be made among different expression systems and different genes. In these systems recombinant proteins are expressed as fusions with GST and MBP, respectively. In general, such fusion proteins are soluble and are easily purified from lysed cells under non-denaturing condition by affinity chromatography with glutathione or amylose matrices. The $26 \mathrm{kDa}$ GST of Schistosoma japonicum, the carrier of the pGEX fusions, is rec- 
ognized by antibodies that cross-react extensively with the $26 \mathrm{kDa}$ S. mansoni GST (Henkle et al. 1990), present in the tegument and subtegumentary parenchymal cells (Trottein et al. 1990). So, if one is using the GST fusion protein as a means to raise high titre antibodies or as a vaccine, the interpretation of immunological studies may be complicated, by the immune response directed against GST (a schistosome derived product), which has to be clearly discriminated. In this regard the use of pMalcri would be an advantage, as maltose binding protein does not cross-react with any Schistosoma antigen. The limitations mentioned above can be diminished if the carrier is released from the fusion proteins by site specific cleavage. On the other hand, as GST itself is a potential vaccine candidate (Dunne et al. 1995), the use of these fusion proteins could be advantageous and could form basis of a two-component vaccine against schistosomiasis. The expression of some fragments of the gene encoding the precursor for $\mathrm{Sm} 15$ was successfully accomplished. The stability of fusion proteins expressed in E. coli can not always be guaranteed. On occasions, fusion proteins may be recognized as foreign and degraded (Marston 1986). Some of the secondary bands seen in Fig. 1 could thus consist of degradation products. It was interesting to note that some parts of the cDNA could be expressed as more stable and abundant products than others.

Although we were very successful in subcloning the genes of interest in pGEX and expressing their recombinant proteins, the antibodies produced against the fusions did not recognize convincingly the parasite antigen counterpart. $\mathrm{Cu}$ riously, these fusion proteins are recognized by rabbit anti-tegumental membrane (R $\alpha \mathrm{M})$ antibodies (data not shown) and antibodies affinity purified from RaM with the the product of expression of the $\lambda \mathrm{gt} 11$ clone A70. As yet, the reasons for these results are not clear but there are some possible explanations: (1) the post translational modifications that occur in eukariotes do not occur in prokariotes. It is possible that these alterations are important for immunogenicity; (2) GST, the carrier of the pGEX vectors, seems to be very immunodominant in comparison to the recombinant proteins of the gene for the Sm15 precursor (Fig. 1A). This may interfere with the immune response against the recombinant part of the fusion protein. However, pMal-cri, an expression vector encoding a different carrier also failed in raising antibodies for immunochemical studies of the parasite; (3) the half life of some products may be very short, due to proteolytic processing.

On the other hand, the same strategy was used for the gene encoding Sm13. In this case the pMal- cri expression vector was used. Antibodies raised in rabbits against the $\mathrm{Sm} 13$ fusion protein recognized in Western blot the $13 \mathrm{kDa}$ tegumental antigen. More detailed immunochemical studies about this atigen will be published elsewhere.

In light of the successful results with pMal-cri regarding the gene for $\mathrm{Sm} 13$, it seems that the final outcome of strategies using expression of heterologous genes in E. coli is not guaranteed. The peculiarities of the gene of interest are important and the choice of the expression system must sometimes be decided on an empirical basis.

\section{REFERENCES}

Abath FGC, Simpson AJG 1990. A simple method for the recovery of purified recombinant peptides cleaved from glutathione-S-transferase-fusion proteins. Peptide Res 3: 167-168.

Abath FGC, Hagan P, Jeffs SA, Schechter I, Meadows HM, Holder AA, Simpson AJG 1993. Structure of the gene encoding a Schistosoma mansoni putative tegumental antigen precursor. Mol Biochem Parasitol 60: 81-92.

Abath FGC, Hagan P, Jeffs SA, Simpson AJG 1994. Partial characterization and kinetics of expression of Sm15, a Schistosoma mansoni tegumental antigen. Parasitol Res 80: 64-69.

Chung CT, Niemela SL, Miller RH 1989. One-step preparation of competent Escherichia coli: transformation and storage of bacterial cells in the same solution. Proc Natl Acad Sci USA 86: 2172-2175.

Dunne DW, Hagan P, Abath FGC 1995. Prospects for immunological control of schistosomiasis. Lancet 345: 1488-1492.

Henkle KJ, Davern KM, Wright MD, Ramos AJ, Mitchell GF 1990. Comparison of the cloned genes of the 26and 28-kilodalton glutathione S-transferases of Schistosoma japonicum and Schistosoma mansoni. Mol Biochem Parasitol 40: 23-34.

Laemmli UK 1970. Cleavage of structural proteins during the assembly of the head of bacteriophage T4. Nature 227: 680-685.

Lyon JA, Weber JL 1988. Preparation and use of monospecific antibodies selected using recombinant expression proteins adsorbed to nitrocellulose, p. 95104. In OJ Bjerrum, NHH Heegaard (eds), Handbook of Immunoblotting of Proteins, Vol. II., CRC Press. Florida.

Marston AO 1986. The purification of eukaryotic polypeptides synthesized in Escherichia coli. Biochem J 240:1-12.

Sambrook J, Fritsch EF, Maniatis T 1989. Molecular Cloning. A laboratory manual, 2nd ed. New York, Cold Spring Harbor Laboratory Press, 1626 pp.

Simpson AJG, Hagan P, Hackett F, Ali PO, Smithers SR 1990. Epitopes expressed on very low Mr Schistosoma mansoni adult tegumental antigens conform to a general pattern of life-cycle cross-reactivity. Parasitology 100: 73-81

Simpson AJG, Schryer MD, Cesari IM, Evans WH, Smithers SR 1981. Isolation and partial character- 
ization of the tegumental outer membrane of adult Schistosoma mansoni. Parasitology 83: 163-177.

Smithers SR, Hackett F, Braga V, Simpson AJG 1990.

Immunoblotting identifies additional antigens recognised by mice protectively vaccinated with adult Schistosoma mansoni tegumental membranes. Parasitol Res 76: 454-456.

Smith DB, Johnson KS 1988. Single-steep purification of polypeptides expressed in Escherichia coli as fusions with glutathione S-transferase. Gene 67: 3140.

Trottein F, Kieny MP, Verwaerde C, Torpier G, Pierce RJ, Balloul JM, Schmitt D, Lecocq JP, Capron A 1990. Molecular cloning and tissue distribution of a 26-kilodalton Schistosoma mansoni glutathione Stranferase. Mol Biochem Parasitol 41: 35-44. 
642 Expression of Recombinant S. mansoni Antigens in E. coli - FGC Abath et al. 